\title{
Analysis of Energy Consumption of Indonesian Flat Glass Industry PT. X Based on Green Industry Standards
}

\author{
Reviana Revitasari ${ }^{1}$ and Bambang Heru Susanto ${ }^{1}$ \\ ${ }^{1}$ Department of Chemical Engineering, Faculty of Engineering, Universitas Indonesia, Depok 16424, Indonesia
}

\begin{abstract}
The natural resource consumption is higher along with the increasing needs of people in various sectors, which affect the environment directly or indirectly. Especially for energy consumption, the supply and availability of fossil energy, as a non-renewable energy, are increasingly depleted and not guaranteed in the long run, coupled with the issue of emissions generated. The industrial sector as a driver of the national economy, including the flat glass industry as a case study, is an energy intensive sector. Almost $83 \%$ of its energy consumption used for operating the furnaces as the main production unit with temperature up to $1700{ }^{\circ} \mathrm{C}$ continuously about 15 years. The increasing of effectiveness and efficiency of energy consumption in the glass manufacturing process will affect significantly to sustainable production in PT. X and gives many other valuable impacts to the economic growth, environment, and society. So, this study analyzes about the energy consumption in PT. X based on Green Industry Standards, believed as a proper strategy, the benchmark of some standards or related regulations for energy consumption in several countries, and the opportunity of the green industry concept implementation in the glass manufacturing process. The methods were studied of literature, plant observation, interview, and data calculation manually and using spreadsheets. The results indicate that the Flat Glass Industry PT. X requires the improvement to increase the effectiveness and efficiency of energy consumption to get the sustainable production.
\end{abstract}

\section{Introduction}

The industrial sector as a driver of the national economy, including the flat glass industry as a case study, is an energy intensive sector. One of the objectives of industrial operation in Indonesia as stated in Law No.3/ 2014 on Industry is to realize an independent, competitive, and advanced industry. In addition, it is expected also the realization of a green industry. It is certainly in line with many global agreements in order to support greenhouse gas (GHG) mitigation, energy security promotion, and solution for various environmental issues and natural resource depletion nationally and globally. In order to support it, Indonesia government set the Green Industry Standard (GIS) to guiding, monitoring, and evaluating easily with measurable evaluation. Nowadays, it still voluntary program, but it will be a mandatory soon. GIS is a result of consensus from several stakeholders, that the representative of government, academia, industry players, and public figure. So that there will be adjustments within the agreed-upon standard, which will be different in other countries. So, it becomes one of the focus reviews in this paper.

Green industry, as stated in the Law of the Republic of Indonesia Number 32014 about Industry, is industries that in the production process, prioritize the efforts of efficiency and effectiveness of resource use (raw material, energy, and water) in a sustainable manner so as to harmonize the development of industry with the sustainability of environmental functions and can provide benefits for the community [1]. This paper focuses on Energy consumption in the glass manufacturing process as a significant point in the production process at Flat Glass Industry.

Flat glass industry PT. X produces flat or sheet glass with a production capacity of 612,500 tons per year. The process technology applied is a Float Process method which has 5 process units, that batch plant, melting furnace, tin bath, annealing Lehr, and cutting line. Raw material composition of glass in PT. X is Silica sand, soda ash, dolomite, feldspar, salt cake, limestone, sodium nitrate, cobalt oxide, nickel oxide, and cullet. Cullet is glass waste reused as raw material for glass manufacture. Its function is very important to reduce energy and raw material consumption with a total composition of 1 mix raw material consists of $25 \%$ of cullet and $75 \%$ of batch composition.

The mixture of feedstock is fed into the furnace and melted at about $1700{ }^{\circ} \mathrm{C}$ to form molten glass using a gas/ fuel burner.The furnace output temperature is about $1100{ }^{\circ} \mathrm{C}$. Then the molten glass is fed to a surface of an $1100{ }^{\circ} \mathrm{C}$ liquid tin covered in liquid called tin bath. Temperature output of Tin bath is about $600{ }^{\circ} \mathrm{C}$. Gradually, the glass is cooled from 600 to $100{ }^{\circ} \mathrm{C}$, after that it is brought to the cutting area. In this area, automatic and manual defects are identified. Glass is cut in jumbo size or as per consumer demand. The edges of the glass bands are cut and recycled into the melting furnace as a cullet [2].

For a $\mathrm{CO}_{2}$ emissions, about $75 \%$ of $\mathrm{CO}_{2}$ emissions from float glass process are sourced from fossil fuels used to burn the furnace, while $25 \%$ comes from process emissions. The 
$\mathrm{CO}_{2}$ source of process emissions is not a function of efficiency, but a chemical process and therefore some emissions will remain, unless new processes are built. However, the use of recycled glass (lower use of raw materials) is increasing, resulting in a reduction in process emissions. There is also an indirect emissions from electricity use (melting and downstream activities). Emissions are not directly as a whole of the sheet glass subsector of about $16 \%$ of total $\mathrm{CO}_{2}$ emissions per finished product $[3,4]$.

The purpose of this research is to get the overview and evaluation of energy consumption in Flat Glass Industry PT. $\mathrm{X}$ based on green industry standards and find the opportunity of decreasing energy consumption and implementation of the green industry concept there.

\section{Experimental details}

This research has begun by conducting a literature review of topics related to the research to understand the various theories that exist in this study, to understand all the issues related to the theme raised and obtain novelty aspects, as well as to determine methodology appropriate to the condition and availability of data in Indonesia, especially for Flat Glass Industry. After that, field observations and interviews have been made to obtain primary and secondary data that have been calculated manually and using spreadsheets. Energy distribution analysis made by using Sankey diagram software with goals as follows:

- Obtain a flow map of the energy distribution with clear and complete definition of each input and output in the whole production process.

- Know the units of processes with a large level of energy consumption and a strong influence on the level of energy consumption in the production process.

- Find out which operating units will be the main targets and have a significant impact on decision making.

The primary data are collected from measurements on energy measuring devices (flow meter, $\mathrm{kWh}$ meter) and plant observations and interviews. The secondary data are gotten from the energy balances (heat and electricity) and actual production data. The limits of the calculated heat and electricity energy consumption are the consumption of heat and electrical energy used for the production process (including utilities), but excluding those used for the office and domestic. The total energy consumption calculated is the sum of heat energy and electricity.

Then PT. X has been evaluated by Green Industry Standard of Flat Glass Industry to know the achievement of PT. X and formulated the recommendation.

The other limitations in this paper are:

a. The data used in this research is taken from Flat Glass Industry PT. X in an industrial area in Indonesia

b. This study focuses on energy consumption for production process of Float 2 (two) in PT. X.

c. The benchmark standards in this study were compared from the following standards or regulations:

1) Green Industry Standard (GIS) from The Ministry of Industry, Indonesia.
2) China Cleaner Production Standard of Flat Glass Industry: HJ/T361-2007.

3) Intergovernmental Panel on Climate Change (IPCC) for Glass Industry

4) Best Available Techniques (BAT) Reference Document for the Manufacture of Glass compiled by the European Commission.

5) Final Report for a study on composition and drivers of energy prices and cost in Energy Intensive industries: The Case of The Flat Glass Industry by Centre for European Policy Studies (CEPS)

6) United States Environment Protection Agency (EPA) and Department of Energy (DOE).

\section{Results and discussion}

\subsection{Benchmark of standards}

Especially in energy sector, there are many standards or regulations have been set in many other countries. The following figure displays the benchmark of some standards globally related to specific total energy consumption in Flat Glass Industry.

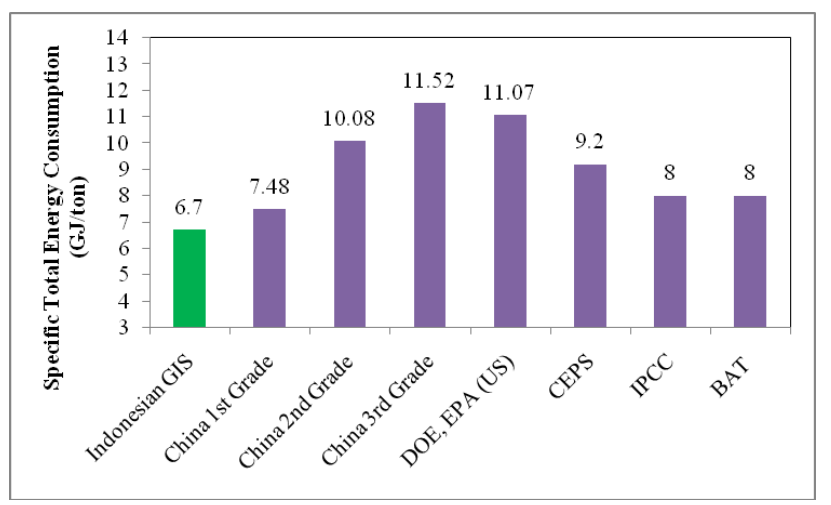

Figure 1. Benchmark of Maximum Specific Total Energy Consumption Standards [3-9].

Figure 1 shows that Indonesian Green Industry Standard is the most stringent standard related to maximum specific energy consumption. Following by China $1^{\text {st }}$ grade standard, IPCC, BAT, China $2^{\text {nd }}$ grade standard, DOE (US), and the highest is China $3^{\text {rd }}$ standard. It indicates that the strong commitment of the Indonesian government, industry players, and academician to support the goals of green industry realization nationally and globally. So, in this paper, Indonesia GIS used as the standard to evaluate the Flat Glass Industry PT. X., that the total energy consumption per sheet of glass products (including cullet) in GIS is a maximum of $6.7 \mathrm{GJ} / \mathrm{ton}[7]$.

In Indonesia Green Industry Standard (GIS), the total energy consumption for production process is divided into 2 energy sources that Electricity and Heat Energy sourced from natural gas and fuel. The following table displays the limitation for each energy consumption in the flat glass industry. 
Table 1. Standard limitation of specific energy consumption in flat glass industry in indonesian green industry standard (GIS).

\begin{tabular}{|l|c|c|}
\hline \multicolumn{1}{|c|}{ Criteria } & $\begin{array}{c}\text { Standard } \\
\text { Limitation }\end{array}$ & Unit \\
\hline $\begin{array}{l}\text { Specific Electricity } \\
\text { Consumption }\end{array}$ & Max 0.7 & GJ/ton \\
\hline $\begin{array}{l}\text { Specific Heat Energy } \\
\text { Consumption }\end{array}$ & Max 6 & GJ/ton \\
\hline $\begin{array}{l}\text { Specific Total Energy } \\
\text { Consumption }\end{array}$ & Max 6.7 & GJ/ton \\
\hline
\end{tabular}

So, the energy consumption in Flat Glass Industry PT. X analyzed and evaluated separately as Table 1, which has distinguished discussion based on its energy source.

\subsection{Energy distribution and consumption}

Flat glass industry PT. X has 3 Float Process Units. Each float produces different glass type and capacity based on process technology, sources of energy, and glass product demand. So that, to get a brief and comprehensive overview and evaluation, conducted the analysis for each float separately. This paper focuses on energy consumption of Float 2.

As described before that flat glass industry is one of the energy intensive sectors. The dominant energy used in the flat glass industry PT. X is natural gas and petroleum. The additional energy is electrical energy. Natural gas is the main fuel for glass production, followed by petroleum products. Both fuels are exchanged in the melting process. More than three quarters of the energy used in the float process comes from glass melting. Furnaces as its main operating unit that operates continuously, and uses up to $83 \%$ of the total energy required for production processes in the industry and operating continuously up to 15 years. The most energy intensive stage of the glass sheet production process is the activity of the furnace, when heating uses natural gas. Figure 2 displays the energy distribution of Float 2 in Flat Glass Industry PT. X. The energy source of Float 2 are Electricity obtained from the State Electricity Company, natural gas, Diesel, and Residue.

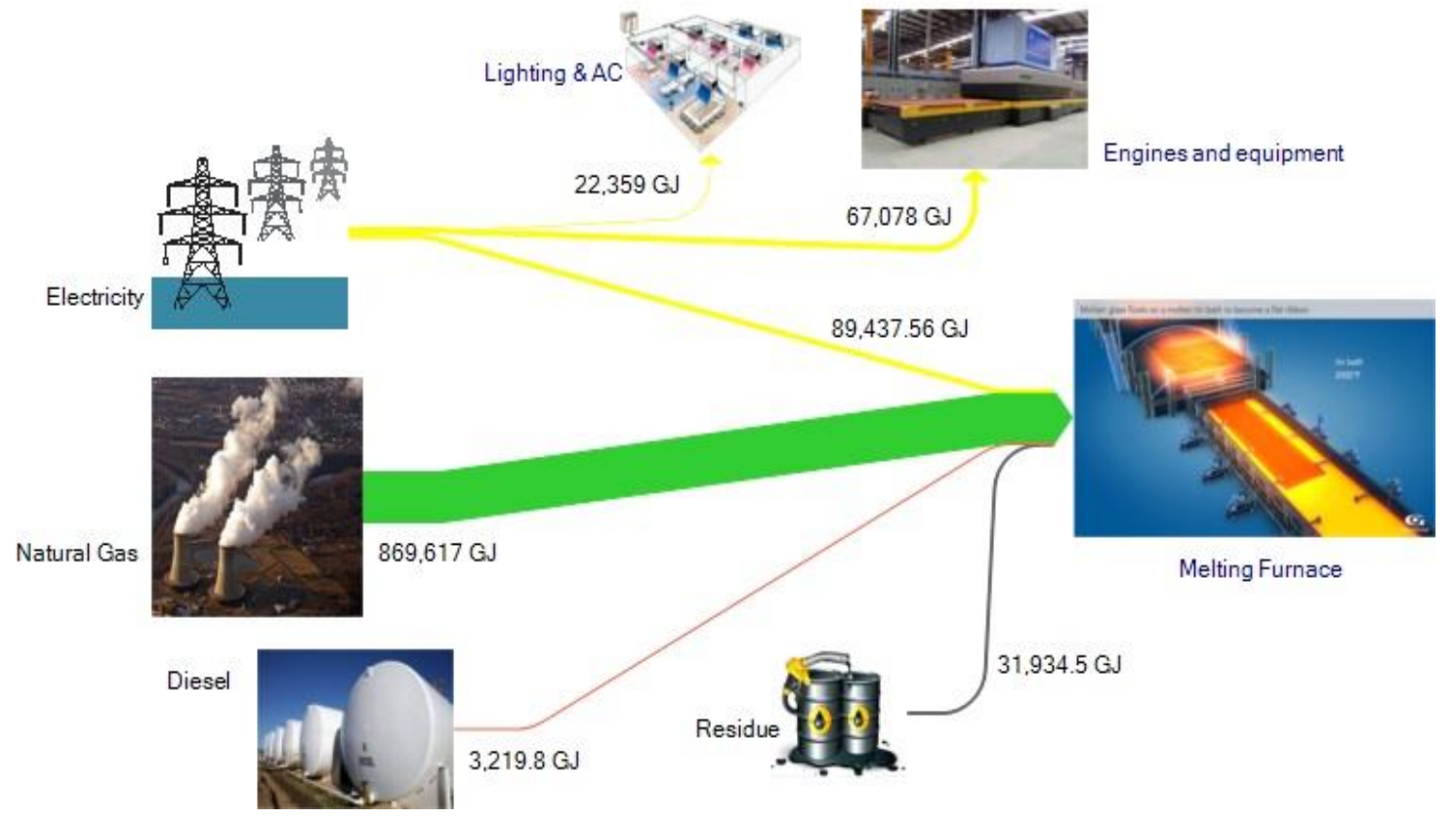

Figure 2. Energy Distribution of Float 2 in Flat Glass Industry PT. X in 2016

From the above figure, it is proven that the highest energy consumption is in the hot end process which melting furnace as the main process unit. So, the improvement recommendation mostly related to the melting process, which is also affected by the previous process.

\subsubsection{Specific heat energy consumption}

The specific heat energy consumption in glass manufacturing is heat energy consumption per sheet of glass products (including cullet). The heat energy consumption data is a total of natural gas, diesel, and residue consumption. The following figure shows the specific heat energy consumption of Float 2 in PT. X.

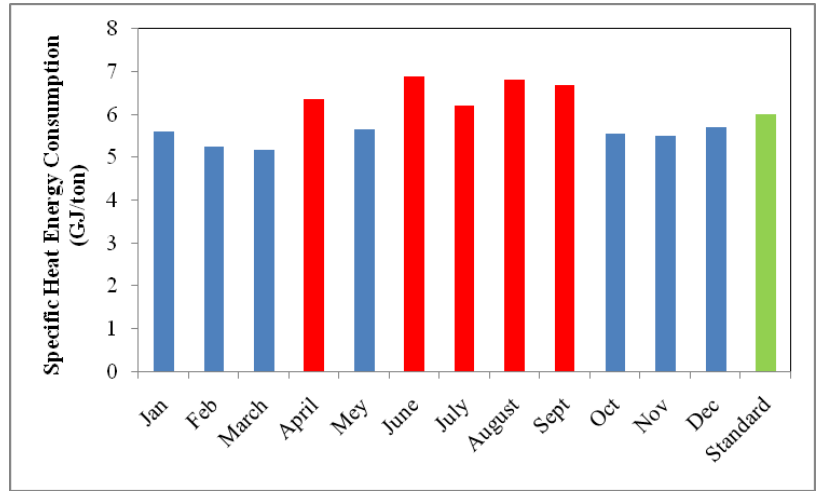

Figure 3. The Specific Heat Energy Consumption of Float 2 in Flat Glass Industry PT. X by month in 2016. 
Figure 3 shows energy consumption of PT. X for 7 months among 2016 under the Indonesian Green Industry Standard. But, there are 5 months which is higher than the limitation standard. As for the standard consumption of heat energy per sheet of glass products (including cullet) is a maximum of $6 \mathrm{GJ} /$ ton [7]. Meanwhile the specific heat energy consumption of PT. X in that 5 months are $6.36,6.88$, $6.22,6.82,6.69 \mathrm{GJ} / \mathrm{ton}$. The average specific heat energy consumption in 2016 is $5.95 \mathrm{GJ} /$ ton.

\subsubsection{Specific electrical energy consumption}

The specific electrical energy consumption is consumption of electrical energy per sheet of glass products (including cullet). The figure 3 displays the specific electrical energy consumption in float 2 of Flat Glass Industry PT. X by month in 2016.

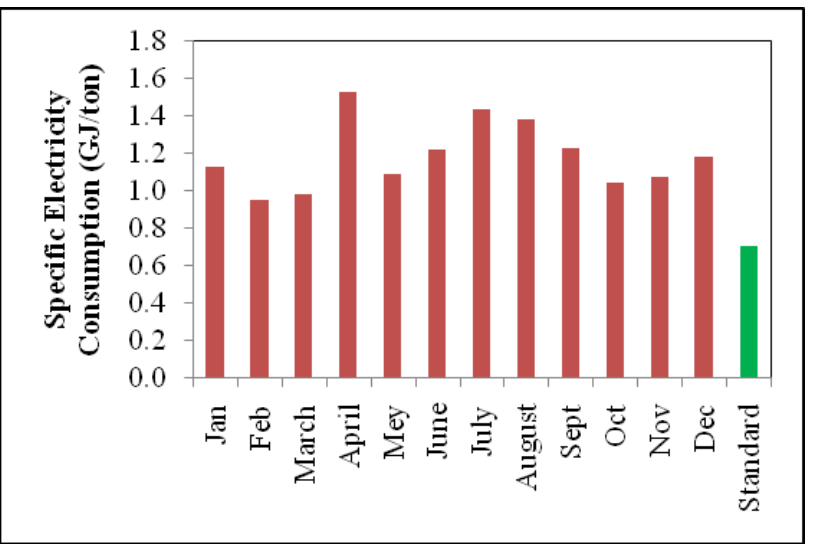

Figure 4. The Specific Electricity Consumption of Float 2 in Flat Glass Industry PT. X in 2016.

For the consumption of electrical energy per sheet of glass products (including cullet) according to the Green Industry standard is a maximum of $0.7 \mathrm{GJ} /$ ton [7]. Figure 4 shows that electrical energy consumption of Float 2 PT. X is higher than limitation standard in each month. The lowest electricity consumption is $0.95 \mathrm{GJ} /$ ton in February and the highest is $1.53 \mathrm{GJ} /$ ton in April 2016. The average specific electricity consumption in 2016 is $1.19 \mathrm{GJ} / \mathrm{ton}$.

\subsubsection{Specific total energy consumption}

The total energy consumption is the sum of heat and electrical energy consumption. Then the specific total energy consumption is the total energy consumption per sheet glass product (including cullet). The figure below displays it compare to limitation standard in Indonesian GIS.

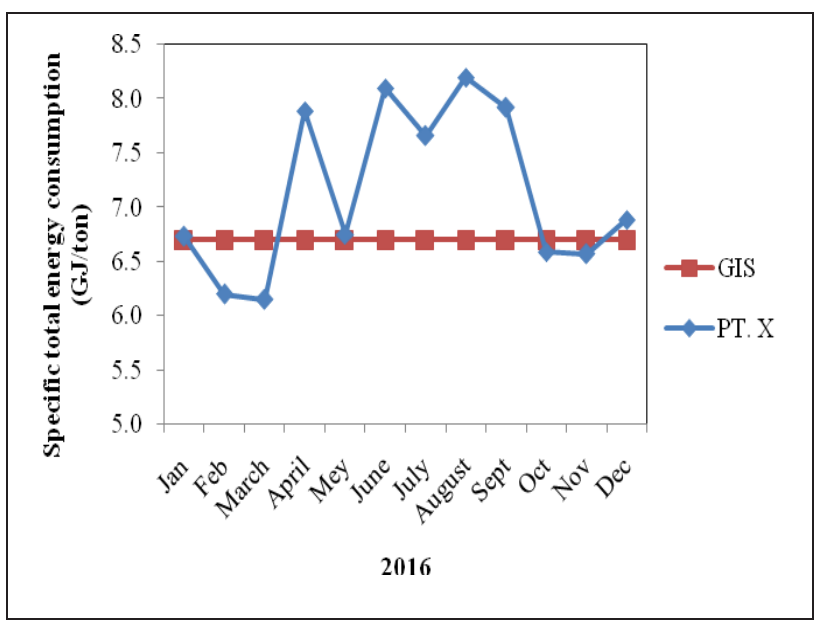

Figure 4. The Specific Total Energy Consumption of Float 2 in Flat Glass Industry PT. X in 2016.

The maximum consumption standard of total energy consumption per sheet of glass products (including cullet) in GIS is $6.7 \mathrm{GJ} /$ ton [7]. The result shows that almost every month, its specific total energy consumption is higher than the GIS standard. The average specific total energy consumption in PT. X in 2016 is $7.14 \mathrm{GJ} /$ ton.

Based on plant study, survey, interview, and data calculation, found several things that cause the amount of energy consumption in float 2 , such as:

a. Changes in glass product demand while operation unit operate continuously

b. Heat loss in the furnace wall

c. No batch and or cullet preheating process before melting process

d. Changes in cullet usage

The use of cullet in a glass furnace can significantly reduce the energy consumption and its use is generally applicable to all types of furnaces. Cullet has a lower melting energy requirement than the constituent raw materials because endothermic chemical reactions associated with glass formation have been completed and its mass is approximately $20 \%$ lower than the equivalent batch materials. Therefore, increasing the cullet level in the batch has the potential to save energy and, as a general rule, every $10 \%$ of extra cullet results in a $2.5-3.0 \%$ reduction in furnace energy consumption. The use of cullet generally results in significant cost savings as a result of the reduction in both energy and raw material requirements [2]. The use of cullet in PT. X depends on the avaibility of internal cullet or cullet in house that glass shards originating from the factory waste itself so as to have a glass composition advantage similar to that produced by the factory. PT. X also use of external cullet called cullet foreign. That cullet from outside the factory or from waste collecting stalls are usually different in composition than factory-produced materials. Their storage must be separated due to different composition. The cullet should also be free of contamination such as oil, ash, metal, packaging materials and others as it will affect the quality of the resulting glass [2]. So, the amount of cullet is limited by the availability of the right quality cullet and proper chemical compatibility. 


\section{Summary}

Flat glass industry is an energy intensive sector. Almost $83 \%$ of its energy consumption used for operating the furnaces as the main production unit with temperature up to $1700{ }^{0} \mathrm{C}$ continuously about 15 years. Besides, its primary energy source is fossil energy. Green industry concept believed as the most proper strategy in encouraging manufacturing industries towards using sustainable patterns of production and economic growth. Green Industry Standard (GIS) was set to guiding, monitoring, and evaluating industry easily with measureable evaluation. It is a consensus result from several stakeholders, that the representation of government, academician, industry players, and public figure. So that there have been adjustment within the agreed-upon standard. In energy sector, limitation standard of Indonesian GIS is the most stringent standard related to maximum specific energy consumption among China Clean production standard, IPCC, BAT, regulation of DOE and EPA (US). It indicates that the strong commitment of Indonesian government, industry players, and academician to support the goals of green industry realization nationally and globally. So, in this paper, Indonesia GIS used as the standard to evaluate the Flat Glass Industry PT. X.

The results showed that the Flat Glass Industry PT. X needs the improvement programs to increase the effectiveness and efficiency of energy consumption, heat as well as electricity. Based on plant study, survey, interview, and data calculation, found several things that cause the amount of energy consumption in float 2, such as:

a. Changes in glass product demand while operation unit operate continuously

b. Heat loss in the furnace wall

c. No batch and or cullet preheating process before melting process

d. Changes in cullet usage

The valuable opportunity in PT. X which is expected increase the effectiveness and efficiency of sustainable production is by increasing the effectiveness and efficiency of the energy. It will have a very significant effect in the decrease the energy consumption, which leads to a reduction in the cost of glass production and GHG emissions. Some alternatives are:

a. Stabilize the Batch and Cullet ratio (B/C ratio)

b. Apply the batch and or cullet preheating process

c. Repair or add the addition insulation in the melting furnace

So by increasing the efficiency of the furnace or melting process will give a very significant effect in the decrease in energy consumption, which leads to a reduction in glass production costs and GHG emissions caused.
The last, the implementation of green industry standards is highly feasible and rewarding, proven with the achievements that have been achieved by PT. X as case study. It can help the industry and government to conduct monitoring and evaluation of the industry as a whole and comprehensive way. So it needs an active cooperation between industry players, academicians, the government and society in realizing a green industry based on the best standards. This study had to be continued to be developed for the advancement of science and expediency for other sectors.

\section{Acknowledgement}

The authors wish to deep sense of gratitude towards Universitas Indonesia, LPDP (Indonesia Endowment Fund for Education), and PT. X.

\section{References}

1. Law of the Republic of Indonesia Number 32014 about Industry

2. PT. X, Report Document of Flat Glass Industry, (Bekasi, Indonesia, 2017)

3. S. B. Maria, G. M. Marcos, S. A. Querol, R. Serge, D. S. Luis, JRC Reference Report: Best Available Techniques (BAT) Reference Document for the Manufacture of Glass. (Publications Office of the European Union, Luxembourg, 2013)

4. C. Egenhofer and L. Schrefler, Final Report for a Study on Composition and Drivers of Energy Prices and Cost in Energy Intensive Industries: the Case of the Flat Glass Industry (Centre for European Policy Studies, Brussels, 2014)

5. Intergovernmental Panel on Climate Change (IPCC) for Glass Industry

6. Ministry of Environmental Protection, the National Environmental Protection Standard of the Republic of China, Clean Production Standard of Flat Glass Industry. HJ/T361-2007(2007)

7. The Ministry on Industry, Republic of Indonesia, Green Industry Standard, Flat Glass Industry, SIH 23111.1:2016 (2016)

8. United States Department of Energy (DOE), Specific Energy Consumption US Flat Glass (2002)

9. United States Environment Protection Agency (EPA), Specific Energy Consumption US Flat Glass (2008) 